\title{
Gender differences in couples' division of childcare, work and mental health during COVID-19
}

\author{
Gema Zamarro $\mathbb{D}^{1,2} \cdot$ María J. Prados $\mathbb{D}^{2}$
}

Received: 31 July 2020 / Accepted: 5 December 2020 / Published online: 16 January 2021

(c) The Author(s), under exclusive licence to Springer Science+Business Media, LLC part of Springer Nature 2021

\begin{abstract}
The current COVID-19 crisis, with its associated school and daycare closures as well as social-distancing requirements, has the potential to magnify gender differences both in terms of childcare arrangements within the household and at work. We use data from a nationally representative sample of the United States from the Understanding Coronavirus in America tracking survey to understand gender differences within households on the impact of the COVID-19 crisis. We study how fathers and mothers are coping with this crisis in terms of childcare provision, employment, working arrangements, and psychological distress levels. We find that women have carried a heavier load than men in the provision of childcare during the COVID-19 crisis, even while still working. Mothers' current working situations appear to have a limited influence on their provision of childcare. This division of childcare is, however, associated with a reduction in working hours and an increased probability of transitioning out of employment for working mothers. Finally, we observe a small but new gap in psychological distress that emerged between mothers and women without school-age children in the household in early April. This new gap appears to be driven by higher levels of psychological distress reported by mothers of elementary school-age and younger children.
\end{abstract}

Keywords Gender · Childcare $\cdot$ Labor participation · Working hours · Mental health · COVID-19

JEL codes $\mathrm{J} 13 \cdot \mathrm{J} 21 \cdot \mathrm{I} 1$

Gema Zamarro

gzamarro@uark.edu

1 University of Arkansas, Fayetteville, AR 72701, USA

2 University of Southern California, Los Angeles, CA 90089, USA 


\section{Introduction}

The COVID-19 pandemic is greatly affecting American households in several important dimensions. The initial response to the public health crisis almost brought the economy to a halt and the unemployment rate jumped to a historical high of $14.7 \%$ in April 2020. ${ }^{1}$ Work conditions for those who remained employed changed abruptly, with many being forced to work from home. Additionally, the closure of schools and childcare centers has meant that households with children are experiencing increased time demands at home. This situation is challenging for workers who work from home as well as for those who continue working outside the house. And, added to the mix is the uncertainty about the resolution of the economic and public health crises.

There are several reasons to believe this pandemic could disproportionately affect working women compared to men in the United States (Alon et al. 2020). First, while prior recessions have affected traditionally male-dominated sectors like manufacturing, construction, or trade, the COVID-19 crisis, and its social distancing requirements, had its biggest effect on more female-dominated sectors, namely the service industry (Mongey and Weinberg 2020). As a result, women's employment appears to have suffered at least as much as men's during this crisis (Montenovo et al. 2020, Adams-Prassl et al. 2020; and for the U.K.: Oreffice and QuintanaDomeque 2020). The possibility to work remotely, however, mitigated some of the negative effects on employment and work hours, especially for self-employed workers (Kalenkoski and Pabilonia 2020).

Second, as schools and daycare centers closed around the country, childcare needs soared. Given that women already carried a heavier load than men in the provision of childcare before the crisis (Aguiar and Hurst 2007, Schoonbroodt 2018), and given that the employment shock in the present crisis initially hit both genders similarly, it is expected that women will continue to carry a heavier load due to the increased childcare responsibilities that have resulted from the crisis. ${ }^{2}$ However, due to the social distancing requirements, more parents are working from home than before. With more parents of both genders spending more time at home during the pandemic, it is unclear, a priori, what this would imply for the gender balance in the division of childcare between parents.

Finally, social-distancing recommendations, stay-at-home orders, and the higher COVID-19 mortality risk of the elderly have made it difficult, if not impossible, for informal care providers, such as grandparents or other family members, to help with childcare responsibilities. This is important because it is well known that childcare arrangements are crucial for female labor supply (Heckman 1974; Baker et al. 2008; Domeij and Klein 2013; Bick 2016; and Zamarro 2020, among others). For all these reasons, the COVID-19 crisis could likely have a major impact on women, especially on their career trajectories and the well-being of working mothers.

\footnotetext{
1 U.S. Bureau of Labor Statistics.

2 It is worth noting that even in the extreme case of the 2007-2009 recession when men's employment was hit harder than women's, and when fathers increased their time devoted to childcare, mothers did not experience significative changes in their time spent in childcare (Gorsuch 2016).
} 
In this paper, we use data from a nationally representative sample of the U.S. from the USC Dornsife Center for Economic and Social Research Understanding Coronavirus in America tracking survey to understand the gender differences on the impact of the COVID-19 crisis. In particular, we document how fathers and mothers are coping during this crisis in terms of childcare provision, employment, working arrangements, and psychological distress levels. While there is emerging literature using survey data to study the gender effects of the COVID-19 crisis, our work makes use of unique rich tracking survey data collected biweekly during the COVID-19 crisis to study the impact of the pandemic on gender equity within households in the U.S.

We find that the increased need for childcare has put a strain on working parents of both genders, but overall, mothers have continued to carry a heavier load on the provision of childcare during this COVID-19 crisis than fathers. Moreover, mothers' current working situation appears to have limited influence on their childcare responsibilities. Additionally, our data show that increased childcare responsibilities are associated with a reduction of working hours and an increased probability of transitioning out of employment during this downturn. Finally, we found that psychological distress increased significantly early into the crisis and a new gap in psychological distress emerged between mothers and women without school-age children. This new gap appeared in April/Early May driven by higher levels of psychological distress among mothers of elementary school-age and younger children. This psychological distress gap between mothers of school-age children and not mothers has been closing since then. However, the large psychological distress gap between mothers and fathers remains.

This paper is organized as follows. Section 2 briefly describes relevant emerging literature while Section 3 describes the data. Section 4 presents our analysis of the gender differences within the household in childcare provision during the crisis. Section 5 presents our results concerning gender effects on working hours and employment. Section 6 describes our results on gender differences in psychological distress, and Section 7 concludes.

\section{Connections to the literature}

Our paper contributes to the emerging but prolific literature on the labor and health effects of the COVID pandemic. Specifically, it relates to the literature highlighting heterogeneous labor market effects of the crisis (Adams-Prassl et al. 2020; Beland et al. 2020; Mongey and Weinberg 2020) and mental health effects by gender (De Pedraza et al. 2020; for several countries; and for the UK: Davillas and Jones 2020; Etheridge and Spantig 2020; and Oreffice and Quintana-Domeque 2020). In this literature, only a few studies use survey data collected during the pandemic and they looked mostly at the short-term effects of the COVID crisis (Farré et al. 2020; Sevilla and Smith 2020; Andrew et al. 2020; and Oreffice and Quintana-Domeque 2020; Adams-Prassl et al. 2020; Collins et al. 2020; Heggeness 2020; Del Boca et al. 2020; Biroli et al. 2020; Villadsen et al. 2020).

Concerning gender imbalances, this literature finds that in the U.S., women spent more time taking care of children than men during March and April 2020 
(Adams-Prassl et al. 2020), mothers with jobs in early school-closure states were more likely than mothers in late school-closure states to have a job but not be working (Heggeness 2020), and mothers reduced their work hours more than fathers (Collins et al. 2020). Similar patterns were observed outside the U.S. In Spain, until May 2020, men increased their participation in housework and childcare slightly, but most of the additional burden fell on women (Farré et al. 2020). In the U.K., women also carried a higher load of childcare duties than men although the gender gap of childcare hours appears to have narrowed as compared to pre-pandemic levels (Sevilla and Smith 2020; Andrew et al. 2020; Oreffice and Quintana-Domeque 2020; Villadsen et al. 2020). In Italy, survey data showed that the division of childcare time depended on working arrangements with both men and women devoting less time to childcare if they continued to work outside the home (Del Boca et al. 2020).

Our paper contributes to this emerging literature in several important ways. First, the richness of our U.S. survey data and large sample size allows us to look at subpopulations by gender, educational attainment, and whether school-age children are living in the household. Second, the tracking nature of the survey data allows us to evaluate the evolution of work engagement and the labor market attachment of workers over time. And lastly, we use four months of data, collected from March to July 2020, to not only look at the initial impact of the lockdown on employment and household arrangements but to also assess the medium-term effects of the pandemic on respondents' employment and wellbeing. Additionally, to our knowledge, this is the first paper that looks at gender differences in mental health in the U.S. during the pandemic.

\section{Data and descriptive statistics}

This paper uses data from eight waves of the Understanding Coronavirus in America Tracking Survey, ${ }^{3}$ collected approximately every two weeks from March 10th to July 22nd, 2020, ${ }^{4}$ administered by the USC Dornsife Center for Economic and Social Research (CESR). Participants in this study are members of the Understanding America Study (UAS). ${ }^{5}$ The UAS is a probability-based household internet panel, comprising a nationally representative sample of approximately 9000 U.S. respondents. ${ }^{6}$ All active respondents in the UAS were asked to participate in the ongoing

\footnotetext{
3 https://covid19pulse.usc.edu/.

4 Wave 1 (March) was collected from March 10, 2020 to March 31, 2020; Wave 2 (Early April) was collected from April 1 to April 28, 2020; Wave 3 (April) was collected from April 15, 2020 to May 12, 2020; Wave 4 (Early May) was collected from April 29, 2020 to May 26, 2020; Wave 5 (Late May) was collected from May 13 to June 9, 2020; Wave 6 (Early June) was collected from May 27 to June 23, 2020; Wave 7 (Late June) was collected from June 10 to July 8, 2020; Wave 8 (Early July) was collected from June 24 to July 22, 2020.

5 The data are publicly available upon registration here: https://uasdata.usc.edu/index.php.

${ }^{6}$ It is important to note that the UAS research team provides internet access and hardware, such as tablets, to those respondents who do not have computer hardware or internet access, so that all households in the sample may participate. UAS respondents usually complete up to 30-minute surveys in waves that occur once or twice per month. Respondents receive compensation for their time spent answering questions at a rate of $\$ 20$ per $30 \mathrm{~min}$ of interview time. The surveys are conducted both in English and Spanish.
} 
Understanding Coronavirus in America Tracking Surveys. Around 7000 respondents agreed to participate in the Coronavirus ongoing surveys.

The UAS panel consists of a representative sample of American households using an address-based sample frame. The recruitment of participants is done through several sample batches. The UAS team uses an adaptative sampling design where addresses from zip codes across the U.S. are randomly selected for recruitment. Each sample batch, however, is adjusted to account for differential nonresponse in prior waves, and zip codes with higher proportions of non-responders are sampled more heavily than those with proportions similar or greater than population proportions. The UAS also includes separate oversamples for Native American respondents, respondents from Los Angeles County, and California populations. However, for each completed survey in the UAS, the UAS team provides sample weights. Sample weights are meant to make each survey data set representative of the U.S. population aged 18 and older concerning gender, race/ethnicity, education, and location.

Once a household is selected to be part of the UAS, all adults aged 18 and older in the household are eligible to participate. Although invited, however, not all members of the household decide to participate and as a result, our analysis focuses on data of each respondent individually. ${ }^{7}$ As we are interested in studying gender differences on the effects of COVID-19 within households, we focus our analysis on those respondents who reported being married or living together with their partners in the same household. About $66 \%$ of our original sample reported being currently married or living together with a partner. We also restrict our sample to working-age respondents who are between 18 and 65 years old, leading to a total of 26,052 observations across the eight waves of data (3980 unique respondents). Sample sizes varied by waves from a minimum of 2826 respondents in wave 2 (Early April) to a maximum of 3605 in wave 1 (March).

Table 1 presents descriptive statistics for our analytical sample of respondents who are married or living together with a partner and who are between 18 and 65 years old. All of our results are weighted to the Current Population Survey (CPS) benchmarks, using UAS provided weights, to account for sample design and nonresponse to maintain national representation to the American population, as described above. Our sample represents all areas of the country with about half of respondents being women and half of the respondents being men. The average age of respondents in the sample is about 44 years old with a majority $(65 \%)$ being white. Ten percent are African American, 20\% are Hispanic or Latino and 6\% are of other races. About $47 \%$ of respondents in our sample reported having school-age children. In our analysis, a respondent is considered to have children in the household if he/she reports living with a school-age child (Kindergarten to 12th grade) or with a child enrolled in daycare or preschool. ${ }^{8}$ About $41 \%$ of respondents reported holding an Associates College degree or higher college education and about $72 \%$ reported

\footnotetext{
7 In our analytical sample including those respondents younger than 65 years old, married or living together with a partner, about $55 \%$ of respondents are the only one in the household participating in the UAS. As a result, less than half of the households in our data would have both partners in the couple responding to the surveys.

8 Throughout this article, we refer to women and men who are part of a couple living with children in the household as mothers and fathers.
} 
Table 1 Descriptive statisticsrespondents who are married or living together with a partner, ages 18 to 65 years old

\begin{tabular}{|c|c|c|}
\hline & Mean & Standard Deviation \\
\hline \multicolumn{3}{|l|}{ Wave size } \\
\hline Wave 1-March & 0.14 & 0.34 \\
\hline Wave 2-Early April & 0.11 & 0.31 \\
\hline Wave 3-April & 0.13 & 0.33 \\
\hline Wave 4- Early May & 0.13 & 0.33 \\
\hline Wave 5-Late May & 0.13 & 0.33 \\
\hline Wave 6-Early June & 0.13 & 0.33 \\
\hline Wave 7- Late June & 0.13 & 0.33 \\
\hline Wave 8- July & 0.12 & 0.33 \\
\hline \multicolumn{3}{|l|}{ Respondents' characteristics } \\
\hline Female & 0.51 & 0.50 \\
\hline Age & 44.30 & 11.74 \\
\hline West & 0.23 & 0.42 \\
\hline Midwest & 0.21 & 0.40 \\
\hline Northeast & 0.17 & 0.37 \\
\hline South & 0.40 & 0.49 \\
\hline White & 0.65 & 0.48 \\
\hline African American & 0.10 & 0.29 \\
\hline Hispanic & 0.20 & 0.40 \\
\hline Other Race & 0.06 & 0.23 \\
\hline College & 0.41 & 0.49 \\
\hline Working in March & 0.72 & 0.45 \\
\hline Can Work from Home & 0.40 & 0.49 \\
\hline Asked to Work from Home & 0.42 & 0.49 \\
\hline School Age Kids & 0.47 & 0.50 \\
\hline
\end{tabular}

Note: Total number of observations was 26,052 observations across the eight waves of data (3980 unique respondents)

Results weighted using population weights to the CPS benchmarks

having a job as of March 2020. For some of our analysis, we further restrict our sample to those respondents who were employed in the same job since March 2020. Among those employed in March 2020, a majority of respondents, about 91\%, kept their jobs in April and subsequent waves. Finally, $40 \%$ of respondents reported in March that they had a job that allows them to work from home while $42 \%$ of respondents reported having been asked by their employer to work from home in the subsequent months. Interestingly, we do not find statistically significant gender differences in either the capacity to work from home in March or having ever been asked by their employer to work from home in the following months. ${ }^{9}$

In the next subsections we describe our measures of childcare arrangements, reduction of working hours, employment and psychological distress that are available

\footnotetext{
9 These results are available from the authors upon request.
} 
in the UAS and show descriptive patterns in the data along these dimensions. In Section 4, we further formalize this analysis.

\subsection{Childcare Arrangements}

Respondents in the UAS who reported living with school-age children were asked in three waves (early April, April, and early May) about childcare responsibilities within the household. In particular, they were asked to identify who was primarily responsible for providing care while schools were closed. ${ }^{10}$ Respondents could answer within the following categories, choosing all that apply: You, your spouse or partner, a sibling, other extended family, a paid childcare provider, a childcare facility not in the home, or other. We then used this information to create the following childcare provision responsibilities indicators: Only me if a respondent only indicated "You" as their answer to the question; Only my partner if the respondent only indicated "Your spouse or partner" as their answer; Only Both if the respondent indicated only both "You" and "Your spouse or partner" as their answer; and Others Help if the respondent indicated other options including "a sibling, other extended family, a paid childcare provider, a childcare facility not in the home, or other" in their response.

Figure 1a shows the patterns of childcare responsibilities as reported in early April, by respondents' gender among those living in two-partner households. Similar patterns were observed in later April and early May. Overall, mothers were taking a heavier load than fathers in providing childcare after schools closed. $45 \%$ of women report being the sole provider of care for their children compared with $14 \%$ of men. These patterns continue even when we condition on those respondents currently working, as it is shown in Fig. 1b. In this case, 33\% of working mothers report that they are the only provider of care for their children compared with about $11 \%$ of working fathers.

\subsection{Working hours and employment}

To study the potential effects of the current COVID-19 crisis on employment, we look at gender differences in changes in the intensive and extensive margins of labor outcomes in our data. UAS respondents answered questions about their employment status in every wave, including a question about whether or not they had to reduce their working hours. We use this question about reducing their working hours as our measure of the intensive margin.

Figure 2 shows the proportion of respondents, among those who held the same job since March, that declared to have reduced their working hours at any time from March to July 2020, by gender, level of education, and whether school-age children are living in the household. As we can see in this figure, a higher proportion of working mothers than working fathers declared having reduced their working hours. Overall, $42 \%$ of working mothers declared to have reduced their hours as compared with $30 \%$ of working fathers. This difference appears to be driven by

${ }^{10}$ By late March 2020, most states in the U.S. had ordered or recommended school closures for the rest of their academic year. 
$\mathbf{a}$

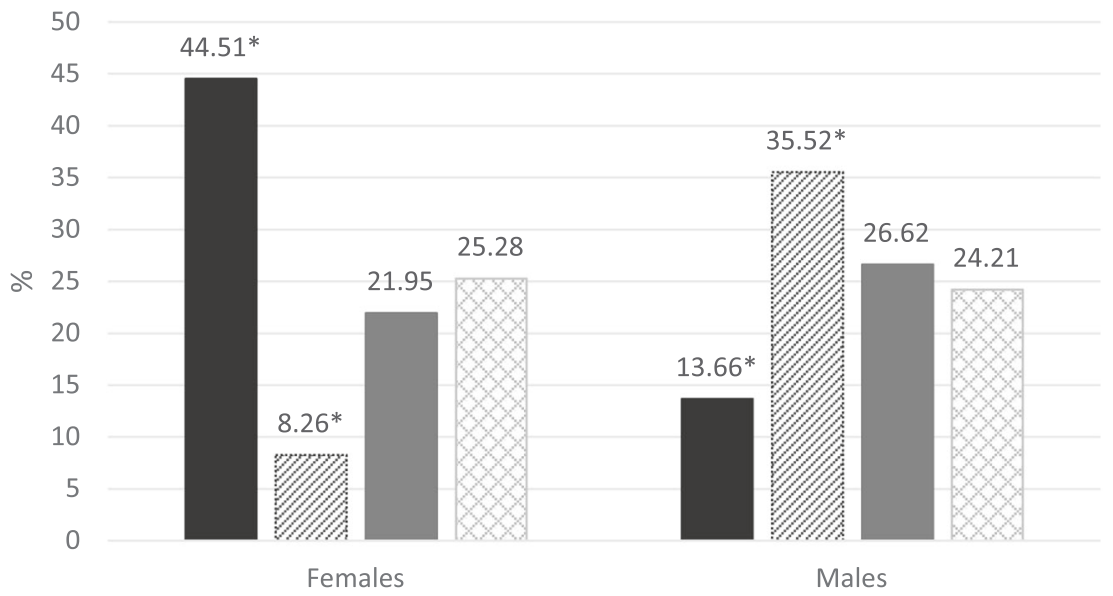

Only Me : Only my partner Only Both $\quad$ Other help

b

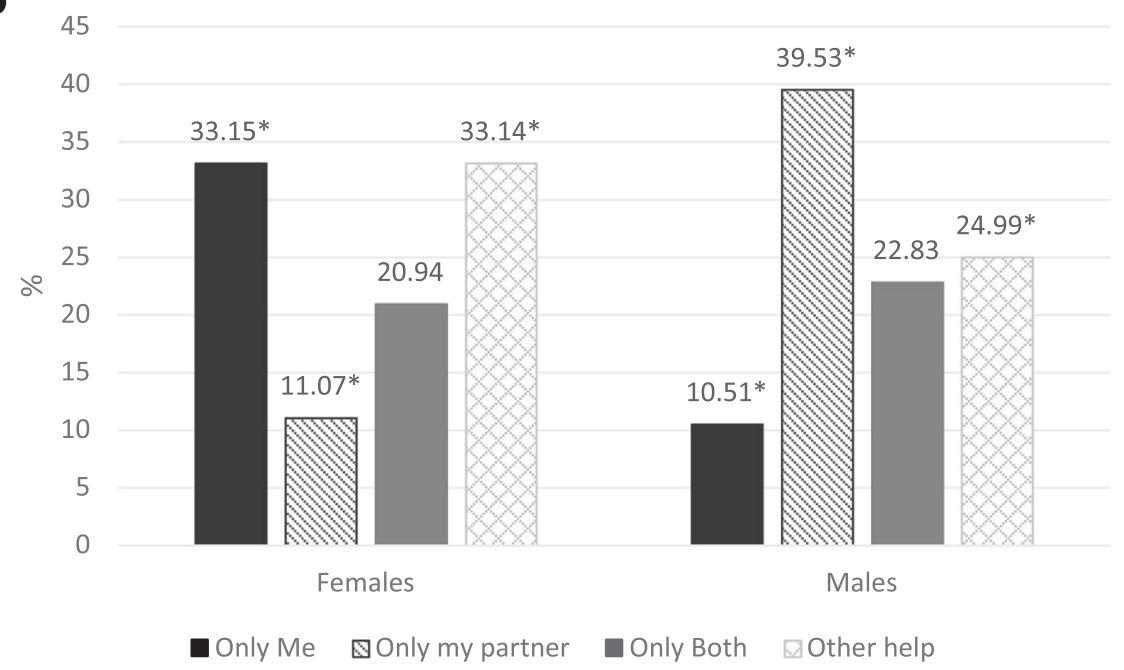

Fig. 1 a "Who is Primary Responsible for Providing Care When School is Closed?" - April 2020, Full Sample. b "Who is Primary Responsible for Providing Care When School is Closed?"- April 2020, Only Those Currently Working. Note: * Denotes statistically significant gender differences at the $95 \%$ confidence level. Results weighted using population weights to the CPS benchmarks

college-educated parents. No statistically significant gender differences are observed among non-college-educated parents. Among working respondents without schoolage children in the household, overall, we do not find a statistically significant gender difference in the proportion of those declaring having to reduce their hours. Around 30 to $35 \%$ of working men and women declared having reduced hours in this case. There is, however, a statistically significant gender difference between non-collegeeducated respondents without young children in the household. About $46 \%$ of 


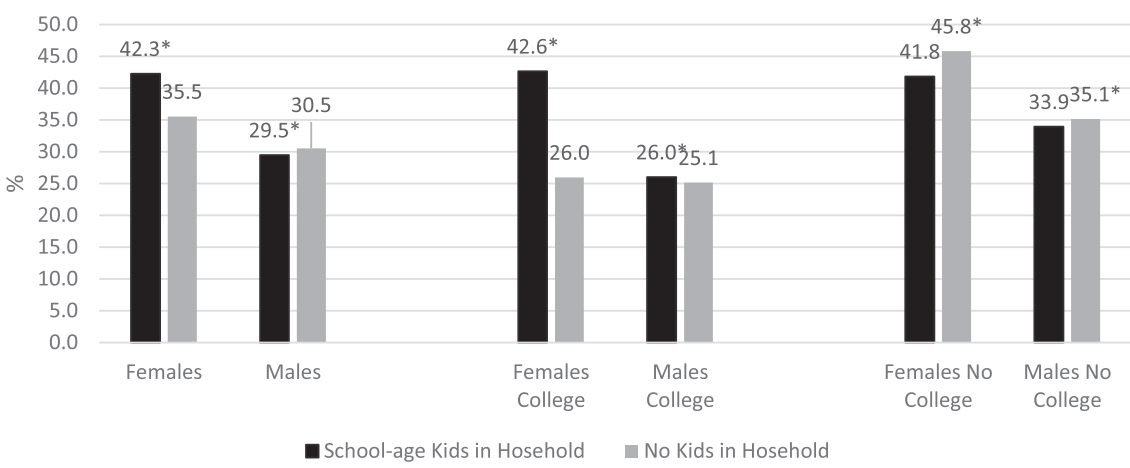

Fig. 2 Ever Reduced Work Hours since March - By Whether Kids in Household. Note: * Denotes statistically significant gender differences at the $95 \%$ confidence level. Results weighted using population weights to the CPS benchmarks

women reported having reduced hours in this case, as compared to $35 \%$ of men. A key limitation of our analysis on working hours, however, is that we are unable to disentangle whether the reduction in working hours is voluntary or whether it was imposed by a respondent's employer through request. To minimize the scope of these other possible drivers, our analysis of working hours focuses on respondents who were currently working at the time of the survey and who held the same job since March, hence we know that the observed differences in hours are not driven by changes in employment status or type of job.

Employment status is another margin that also might change to help accommodate childcare needs. Figure 3 presents the percentage of respondents who declare being employed by survey wave, gender, and level of education. Overall, we do not find statistically significant gender differences in drops of employment during this COVID-19 crisis among those respondents who are married or living together with a partner. ${ }^{11}$ Respondents without a college degree suffered larger drops in employment than college-educated workers. We observe around a 14 and 15 percentage points drop in the proportion of non-college-educated women and men, respectively, declaring being employed in April 2020 compared with March (from 55 to $41 \%$ for women and from 74 to $59 \%$ for men). The drops in employment were much smaller for those holding a college degree. In this case, both college-educated men and women suffered comparable drops of about 9 and 10 percentage points respectively (from 80 to $72 \%$ for women and from 90 to $81 \%$ for men).

Employment rates have started to partially recover since April for all groups except for college-educated women. Although the levels of employment in July 2020 remain statistically significantly lower at the $95 \%$ significance level than in March 2020 for all groups, college-educated men and non-college-educated respondents experienced statistically significant recoveries in their levels of employment by July, compared to those observed after the largest initial shock in April. Employment rates for college-educated men appear to have almost fully recovered by July. However,

${ }^{11}$ On average, women were 4 percentage points more likely than men to lose their jobs in April 2020, but the difference is not significative once we control for education and gender-education interactions. 


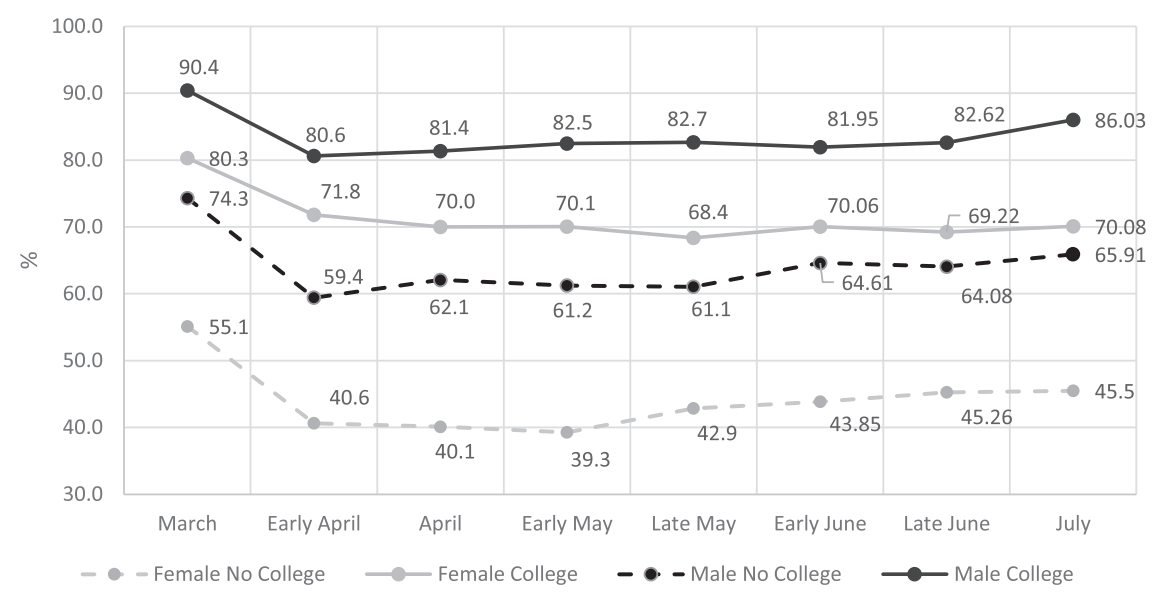

Fig. 3 Percentage of Employed Respondents, Married Or Living Together, By Gender And Level Of Education. Note: Results weighted using population weights to the CPS benchmarks

employment levels for those non-college-educated respondents and college-educated women remain around 10 percentage points lower as of July than those observed in March (46\% for non-college-educated women, $70 \%$ for college-educated women, $66 \%$ for non-college-educated men), and we do not observe a statistically significant recovery in employment by July for college-educated women. In Section 4, we further study the connection between childcare arrangements in the household, gender and work arrangements.

\subsection{Psychological distress}

Looking at the evolution of psychological distress can help understand how households are coping with the new challenges brought about by the crisis, including changes in household arrangements in terms of childcare and work. The UAS Understanding Coronavirus in America tracking Survey collected information on respondents' psychological distress in every survey wave through the Patient Health Questionnaire-4 (PHQ-4) scale of psychological distress (Kroenke et al. 2009a). The PHQ-4 was drawn from the Generalized Anxiety Disorder-7 scale (GAD-7; Spitzer et al. 2006) and the Patient Health Questionnaire-8 (PHQ-8; Kroenke et al. 2009b) and found to accurately measure symptoms of depression and anxiety with just a four-item scale (Kroenke et al. 2009a; Lowe et al. 2010). The four items of the PHQ4 scale include the respondent's frequency of feelings of anxiety, not being able to control worrying, little interest, or pleasure in doing things, and feelings of depression and hopelessness. Respondents reported the frequency of these feelings in four response categories: "0. Not at all"; "1. Several days"; "2. More than half the days" and "3. Nearly every day". Anxiety and depression subscales, ranging from 0 to 6 , are calculated by adding the scores for the two anxiety and two depression related questions, respectively. The PHQ-4 psychological distress score is then calculated by adding the anxiety and depression subscales. For each subscale, as well as for the 


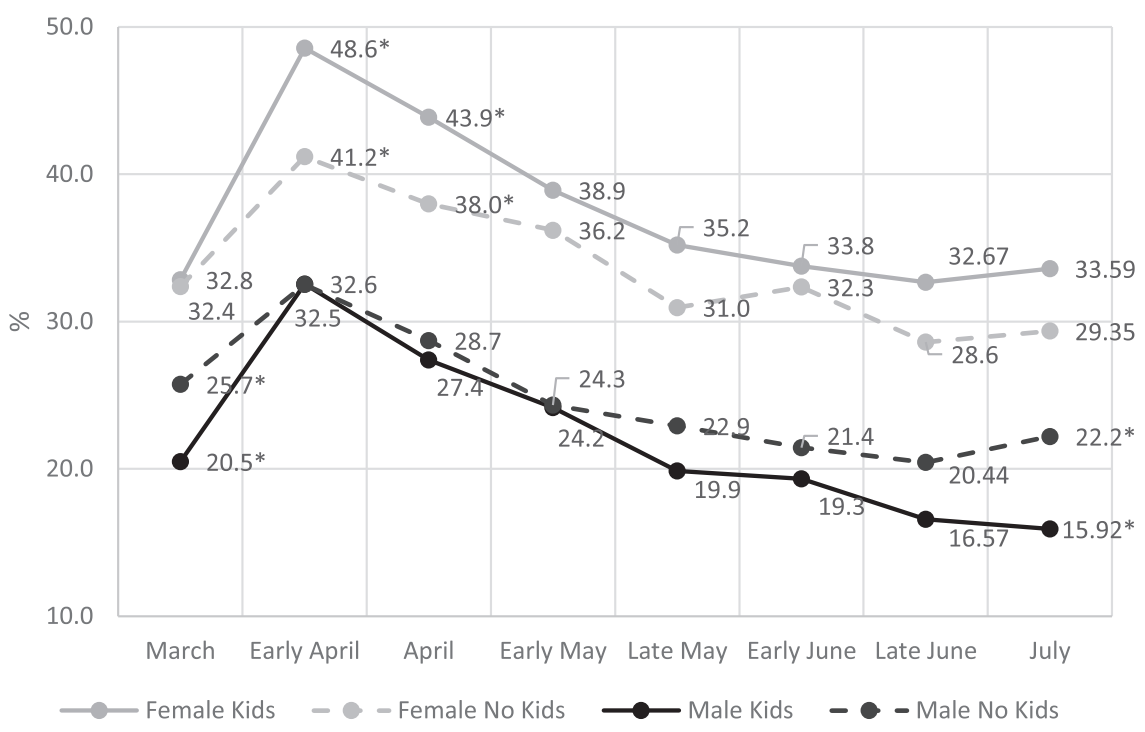

Fig. 4 Psychological Distress During the COVID-19 Crisis-Among Those Married or Living Together By Gender and Whether There Are School Age Kids in the Household. Note: * Denotes statistically significant differences within gender among those with and without school-age children in the household at the $95 \%$ confidence level. Results weighted using population weights to the CPS benchmarks

PHQ-4 scale, a respondent with a score of 3 or more is considered to have at least mild symptoms.

Figure 4 shows the evolution of the percentage of respondents with at least mild symptoms of psychological distress from March to July 2020. Psychological distress symptoms peaked in April with mothers of school-age children in the household presenting the highest rates of psychological distress. $49 \%$ of mothers presented at least mild symptoms of psychological distress in early April. A new gap in psychological distress emerged between mothers and women without school-age children in the household which persisted throughout April. This gap seems to have reappeared in late June and July, although the difference in psychological distress between mothers and women without school-age children is only marginally significant at the $10 \%$ significance level in this case. Fathers of school-age children also experienced higher levels of psychological distress during April, but this jump only helped to equate them to the levels of men without children in the household. As of July, fathers presented lower levels of psychological distress than men not living with school-age children in the household. All groups except women with children in the household have recovered from April's shock in psychological distress and presented lower rates of at least mild psychological distress in July than in March. Psychological distress rates were about 3 percentage points lower in July than March for both women and men without young children in the household. For men with young children in the household, psychological distress rates were almost 5 percentage points lower in July than in March. In contrast, for mothers with young children in the household psychological distress rates were still about 1 percentage point higher in July than in March. 


\section{Gender differences in childcare provision during the COVID-19 crisis}

In this and the next sections, we present our analytical approach and results to further study gender differences in childcare provision, hours worked, employment transitions, and psychological distress, among respondents married or living together with a partner, during the COVID-19 crisis. We start by further analyzing gender differences in childcare provision. On average, married or partnered women tend to be in charge of home production and childcare responsibilities more than men (Aguiar and Hurst 2007; Schoonbroodt 2018) and our descriptive analysis above suggests that continued to be the case in the U.S. during this COVID-19 crisis. In this section, we further study the determinants of parental arrangements of childcare responsibilities in the face of school closures and changes in work status. First, we look at the factors associated with different choices for childcare during April and May 2020. Then, we study the dynamics behind changes in childcare responsibilities.

\subsection{Methods}

We use a multinomial discrete choice logit model to study the determinants of observed childcare arrangements, within two-parent households with school-age children, while schools were closed during the COVID-19 crisis. In particular, we pool waves 2-4 (early April, April, and early May) and estimate models with the following specification:

$$
\begin{aligned}
& \operatorname{Pr}\left(\text { Care }_{i t}=j \mid X\right)= \Lambda\left(\beta_{0}+\gamma_{t}+\beta_{1} \text { Race }_{i}+\beta_{2} \text { Region }_{i}+\beta_{3} \text { Age }_{i}\right. \\
&+\beta_{4} \text { Female }_{i}+\beta_{5} \text { College }_{i}+\beta_{6}{\text { Female } * \text { College }_{i}} \\
&\left.+\beta_{7} \text { Working }_{i}+\beta_{4} \text { Female } * \text { Working }_{i}\right) \\
& j=\text { OnlyMe } ; \text { Only My Partner } ; \text { Only Both } ; \text { Others Help }
\end{aligned}
$$

$t=2,3,4$

The dependent variable Care $_{i t}$ can take four different values depending on the respondent reporting that they were primarily responsible for the provision of care to their children during the time of school closures (Only Me), whether or not their partner was primarily responsible (Only My Partner), both they and their partner were responsible (Only Both) or whether they had help from others (Others Help). Under the assumption of independence of irrelevant alternatives and error terms that are independently and identically extreme value distributed, we estimate the model using maximum likelihood. We include wave fixed effects in the model to take into account the evolution over time of the COVID-19 crisis. We include three regional dummies for the region of residence of the respondent (Midwest, Northeast, and South), four dummies for the respondent's age group (age 18-29, age 30-39, age 40-49, and age 50-59), and three dummies for the respondent's race/ethnicity (African American, Hispanic and other non-white). We control for the respondent having a college degree or higher education allowing for a different effect for women, as compared to men. Our estimated coefficients of interest are those for a female dummy, a dummy for the respondent currently working, and the interaction of 
Table 2 Who is primary responsible of providing care while schools are closed? (marginal effects)

\begin{tabular}{lrrrr}
\hline & \multicolumn{1}{l}{ Only me } & \multicolumn{1}{c}{ Only my partner } & \multicolumn{1}{c}{ Only both } & \multicolumn{1}{c}{ Others help } \\
\hline Female & $0.232 * * *(0.045)$ & $-0.135^{* * *}(0.049)$ & $-0.057(0.048)$ & $-0.040(0.049)$ \\
College & $0.117 * *(0.046)$ & $-0.104 * * *(0.030)$ & $0.124 * * *(0.032)$ & $-0.137 * * *(0.039)$ \\
Female*College & $-0.107 *(0.055)$ & $0.123 * *(0.050)$ & $-0.011(0.046)$ & $-0.006(0.052)$ \\
Working & $-0.307 * * *(0.046)$ & $0.227 * * *(0.038)$ & $-0.008(0.038)$ & $0.089 * *(0.042)$ \\
Female*Working & $0.124 * *(0.055)$ & $-0.173 * * *(0.054)$ & $-0.005(0.050)$ & $0.053(0.056)$ \\
\hline
\end{tabular}

Note: Standard Errors in parenthesis

$* p<0.1 ; * * p<0.05 ; * * * p<0.01$

Number of Observations: 3821. Wave, race, age, and region of residence controls included

Results weighted using population weights to the CPS benchmarks

Table 3 Who is primary responsible of providing care while schools are closed?-Among those currently working (marginal effects)

\begin{tabular}{lrrrr}
\hline & \multicolumn{1}{c}{ Only Me } & Only My Partner & \multicolumn{1}{c}{ Only Both } & \multicolumn{1}{c}{ Others Help } \\
\hline Female & $0.272 * * *(0.048)$ & $-0.407 * * *(0.063)$ & $0.066(0.050)$ & $0.069(0.048)$ \\
College & $0.019(0.052)$ & $-0.065(0.044)$ & $0.107 * *(0.046)$ & $-0.061(0.044)$ \\
Female*College & $-0.081(0.064)$ & $0.172 * *(0.076)$ & $-0.040(0.069)$ & $-0.051(0.070)$ \\
Working at Home & $0.100 *(0.053)$ & $-0.108 * *(0.044)$ & $0.148^{* * *}(0.044)$ & $-0.140^{* * *}(0.046)$ \\
Female*Working & $-0.011(0.066)$ & $0.091(0.076)$ & $-0.118^{*}(0.063)$ & $0.037(0.070)$ \\
at Home & & & & \\
\hline
\end{tabular}

Note: N. Obs. 2137. Standard Errors in parenthesis

$* p<0.1 ; * * p<0.05 ; * * * p<0.01$

Wave, race, age, and region of residence controls included

Results weighted using population weights to the CPS benchmarks

female and currently working. These coefficients help us respond to the question of to what extent mothers are providing more care than fathers and to what extent they are combining care with work. Estimated coefficients are presented as average marginal effects in Table 2 and explained in Section 4.2. Additionally, we estimate separate models for those respondents currently working that control for having been asked by the employer to work from home and an interaction term between female and working from home (Table 3).

One important limitation of the analysis described in (1) above is that, as we do not have access to similar data before the COVID crisis, we are only able to describe the current arrangements in care provision during the time of analysis and are not able to talk about changes that might have occurred compared to a pre-COVID period. However, we might expect and can study changes in childcare provision during the crisis. To this end, because being the only childcare provider is challenging for working parents, we also estimate a discrete duration model for the probability of becoming the sole provider of childcare in the household. A respondent is considered to transition into the sole provider role in the current wave if they did not declare to be the only person providing childcare (i.e. they declared either their partner was the sole provider of care, or they shared childcare responsibilities only 
Table 4 Probability of becoming the sole provider of child care (marginal effects)

All Parents

(1)

\begin{tabular}{lrrr}
\hline Female & $0.081 * *(0.033)$ & $0.172 * * *(0.042)$ & $0.258 * * *(0.052)$ \\
College & $0.045(0.032)$ & $-0.043(0.031)$ & $-0.051(0.040)$ \\
Female*College & $-0.100 * *(0.041)$ & $-0.033(0.041)$ & $-0.043(0.050)$ \\
Working & $-0.170 * * *(0.035)$ & \\
Female*Working & $0.115 * * *(0.041)$ & & \\
Working from Home & & $0.131 * * *(0.041)$ & $0.189 * * *(0.054)$ \\
Female* Working Home & 1951 & $-0.107 * *(0.047)$ & $-0.180 * * *(0.061)$ \\
Observations & & 1262 & 965 \\
\hline
\end{tabular}

Note: Standard Errors in parenthesis

$* p<0.1 ; * * p<0.05 ; * * * p<0.01$

Wave, race, age, and region of residence controls included

Results weighted using population weights to the CPS benchmarks

with their partner, or they have others' help) in early April and the preceding wave but reported being the sole provider of care in the current wave $t$ (April or early May). In particular, we follow this logistic discrete duration model:

$$
\begin{aligned}
& \operatorname{Pr}\left(\text { Only } M e_{i t}=1 \mid X, \text { Only } M e_{i t-1}=0\right) \\
& =\Lambda\left(\beta_{0}+\gamma_{t}+\beta_{1} \text { Race }_{i}+\beta_{2} \text { Region }_{i}+\beta_{3} \text { Age }_{i}\right. \\
& +\beta_{4} \text { Female }_{i}+\beta_{5} \text { College }_{i}+\beta_{6} \text { Female } * \text { College }_{i} \\
& \left.+\beta_{7} \text { Working }_{i}+\beta_{4} \text { Female }^{*} \text { Working }_{i}\right)
\end{aligned}
$$

$t=3,4$

This discrete-time hazard model can be interpreted as the probability of transitioning in wave $t$ to the sole provider of care role, given the respondent has survived not being the sole provider of care to that point. The dependent variable Only $M e_{t}$ takes value one if a respondent is observed transitioning into the role of the sole provider of childcare in the household in wave $t$. The control variables are as those defined in (1) above. We also estimate separate models for those currently working with explanatory variables working from home and the interaction of this variable with the female dummy. Estimated coefficients are presented as average marginal effects in Table 4, columns 2 and 3. In both models (1) and (2), we obtained cluster robust standard errors at the individual level to take into account the fact that we have multiple observations per respondent.

\subsection{Results}

Tables 2 and 3 show average marginal effects from the multinomial logit models for the determinants of childcare arrangements during school closures across the three waves of data available, following the specification explained in (1) above. Table 2 focuses on the childcare provision of working-age respondents, living in two-parent households, with school-age children. Overall, women in couples are 23 percentage 
points more likely than men to say they are the only provider of care for their children, and 14 percentage points less likely to say that their partner is the only provider of care. Having a college degree increases the fathers' probability of reporting being the only provider of childcare by about 12 percentage points and reduces the probability of having a partner who provides all the care by 10 percentage points. However, for women, having a college degree has no significant effect on the probability of being the sole provider of care or having a partner who is. Finally, having a college degree increases the probability of both partners providing childcare together by 12 percentage points and reduces the probability of receiving outside help by 14 percentage points. Those currently working have a lower probability of reporting being the only providers of care for their children and a higher probability of reporting that their partner is the sole provider of care. However, this effect is bigger for men than for women. Working men have a 30 percentage points lower probability of reporting being the sole provider of care and a 23 percentage points higher likelihood of having a partner who is the sole provider of childcare. In contrast, working women only have an 18 percentage point lower probability of being the sole provider of care and a non-significantly higher probability of having a partner who is the sole provider. This result suggests that working mothers are combining childcare and work more so than working fathers.

Table 3 presents the results for working parents, controlling for whether or not they work from home. Even while currently working, working mothers continue to be 27 percentage points more likely to be the only providers of care than working fathers are and 41 percentage points less likely to report that their partner is the only provider of care. Having a college degree increases the probability of reporting that both members of the couple are providing childcare together by 11 percentage points and it increases the probability of working women having a partner who provides all the childcare by 17 percentage points. Parents who were required to work from home are 10 percentage points more likely to be the sole provider of care and 11 percentage points less likely to have a partner who provides all of the care. These effects are very similar for working mothers as well as working fathers. Working from home, fathers are also 15 percentage points more likely to report that both partners provide childcare together. There is no equivalent significant effect, however, for mothers who work from home. Parents working from home do report receiving less help from others outside the household. Controlling for whether or not the respondents are working from home dissipates some of the effects of education. This result is consistent with the fact that college-educated workers are more likely to be able to work from home. ${ }^{12}$

Table 4 presents the results of the discrete duration model for the probability of becoming the sole provider of childcare in the household described in (2) above. The first column of this table presents the overall results for two-parent households with school-age children. The second and third columns present results for the sample of working parents and the sample of working parents who held the same job since March, respectively. Mothers not only have a higher probability of being the only ones in the household providing care to their children, as we saw above,

12 In our sample, $58.5 \%$ of workers with a college degree report being able to work from home to perform their job, while only $22.6 \%$ of non-college degree workers report being able to do so. 
but they are also more likely to have become the sole provider of care even if they were not at the beginning of the COVID-19 crisis in early April. Mothers are 8 percentage points more likely to become the sole provider of childcare than fathers. This effect is bigger for working parents: Working mothers are 17 percentage points more likely to become the only providers of care and 26 percentage points more likely among those holding the same job since March. Being currently employed reduces the probability of fathers becoming the sole provider of childcare by 17 percentage points. However, this scenario is not the case for mothers; they experience the same probability of becoming the sole childcare provider independent of whether or not they are currently working. Having a college degree reduces the probability of becoming the sole provider of care for women, but this effect is not statistically significant for working mothers. Working from home increases the probability of fathers becoming the only provider of childcare, but less so for mothers.

Becoming the sole provider of care is the most extreme transition in terms of childcare load, but other transitions that increase the childcare responsibility of a parent can also be of interest. In this respect, we have also considered models for the transition between "Others Help" or "Only My Partner" to an increased childcare responsibility of "Only Both" or "Only Me". The results of these models can be found in Appendix Table 9. Overall, with all these models we find that mothers have been carrying a heavier load of childcare during this COVID-19 crisis than fathers have, and the current working status appears to have a limited influence on the childcare mothers are providing.

\section{Gender Effects in Working Hours and Employment During the COVID-19 Crisis}

It is well known that childcare arrangements are crucial for female labor supply (Heckman 1974; Baker et al. 2008; Domeij and Klein 2013; Bick 2016; among others). Therefore, we turn to study the impact of childcare arrangements on changes in working hours and employment during the pandemic.

\subsection{Methods}

To accommodate the drastic increase in childcare needs during this COVID-19 crisis, some parents might have had to reduce their working hours. This fact could be especially the case for working mothers, because, as discussed in the previous section, they appear to be carrying a heavier load of childcare needs for the couple despite their current work status.

To further study to what extent respondents have had to reduce their working hours to cope with the increased childcare needs of the COVID-19 crisis, we focus the analysis on those respondents who held the same job since March 2020 and build a variable that takes value one if the respondent reports anytime from April to July that they had to reduce their working hours. We do so to avoid effects derived from changes in employment or type of job. We then estimate the following logistic 
regression:

$$
\begin{aligned}
& \operatorname{Pr}\left(\text { Reducing Hours }_{i} \mid X\right)=\Lambda\left(\beta_{0}+\beta_{1} \text { Race }_{i}+\beta_{2} \text { Region }_{i}+\beta_{3} \text { Age }_{i}\right. \\
& +\beta_{4} \text { Female }_{i} * \text { College }_{i}+\beta_{5} \text { Male } * \text { College }_{i} \\
& +\beta_{6} \text { Female }^{*} \text { NoCollege }_{i}+\beta_{7} \text { Female }^{*} \text { College } * \text { Kids }_{i} \\
& +\beta_{8} \text { Male } * \text { College } * \text { Kids }_{i}+\beta_{9} \text { Female } * \text { NoCollege } * \text { Kids } s_{i} \\
& +\beta_{10} \text { Male } * \text { NoCollege } * \text { Kids }_{i}+\beta_{11} \text { EverWorkFromHome }_{i} \text { ) }
\end{aligned}
$$

The main coefficients of interest are those of the interaction terms of gender, education, and whether school-aged children are living in the household. Estimated coefficients are presented as average marginal effects where the reference category is non-college-educated men without young children in the household in Table 5, column 1. We controlled for age, race/ethnicity, and region of residence with the same variables as described in (1) above. We also include a control variable for respondents reporting if they have ever been required by their employer to work from home.

We run separate specifications for those respondents living with school-age children in the household and replace the interaction terms of gender, education, and whether school children are living in the household in (3) (Female*College*Kids, Male*College*Kids, Female*NoCollege*Kids, and Male*NoCollege*Kids) with variables representing the division of childcare duties in the household, in Table 5,

\begin{tabular}{|c|c|c|c|}
\hline & $\begin{array}{l}\text { All } \\
(1)\end{array}$ & $\begin{array}{l}\text { Parents } \\
\text { (2) }\end{array}$ & $\begin{array}{l}\text { Parents } \\
\text { (3) }\end{array}$ \\
\hline Female $*$ College & $-0.089(0.067)$ & $0.058(0.072)$ & $0.048(0.069)$ \\
\hline Male $*$ College & $-0.144 * *(0.073)$ & $-0.103(0.071)$ & $-0.097(0.069)$ \\
\hline Female* No College & $0.080(0.065)$ & $-0.076(0.080)$ & $-0.074(0.073)$ \\
\hline Female $*$ College $*$ Kids & $0.174 * * *(0.061)$ & & \\
\hline Male* College $*$ Kids & $0.089(0.067)$ & & \\
\hline Female $*$ No College $*$ Kids & $-0.076(0.071)$ & & \\
\hline Male* No College $*$ Kids & $0.000(0.067)$ & & \\
\hline Ever Work from home & $-0.041(0.037)$ & $-0.044(0.053)$ & $-0.033(0.053)$ \\
\hline Ever Only Me & & $0.044(0.057)$ & \\
\hline Ever Only Partner & & $-0.063(0.055)$ & \\
\hline Ever Others Help & & $-0.134 * * *(0.051)$ & \\
\hline Always Me & & & $0.202 * * *(0.068)$ \\
\hline Observations & 1442 & 669 & 669 \\
\hline
\end{tabular}
column 2. In particular, we first include dummies indicating whether the respondent ever reported being the only provider of childcare (Ever Only Me), whether the respondent reported his partner was ever the only provider of care (Ever Only

Table 5 Probability of reducing hours among those holding the same job since march (marginal effects)

Note: Standard Errors in parenthesis

$* p<0.1 ; * * p<0.05 ; * * * p<0.01$

Race, age, and region of residence controls included

Results weighted using population weights to the CPS benchmarks 
Partner), and whether they ever had help from others for childcare (Ever Others Help). We estimate an additional specification that includes an indicator variable for the respondent reporting being the only provider of child-care in the household in all waves (Always Me), instead (Table 5, column 3).

Among those employed in March, we further study the determinants of transitions out of employment in subsequent waves of data from April to July. To do so, we estimate a discrete duration model for the probability of leaving employment in a subsequent wave. A respondent is considered to transition out of employment in the current wave if he/she was observed holding a job in March and the preceding wave but reported being laid off or on leave or another job status in the current wave. Those respondents who find a new job after being observed transitioning out of employment are considered as a new employment duration spell. In particular, we estimate the following logistic discrete duration model:

$$
\begin{aligned}
& \operatorname{Pr}\left(\text { Leaving Employment }_{i t} \mid X\right)=\Lambda\left(\beta_{0}+\gamma^{t}+\beta_{1} \text { Race }_{i}+\beta_{2} \text { Region }_{i}+\beta_{3} \text { Age }_{i}\right. \\
& +\beta_{4} \text { Can Work Home } \text { Ho }_{i}+\beta_{5} \text { Female }_{*} \text { Can Work Home }{ }_{i} \\
& +\beta_{6} \text { Kids }_{i}+\beta_{7} \text { Female }_{*} \text { Kids }_{i}+\beta_{8}^{t} \text { Female }^{*} \text { College }_{i} \\
& \left.+\beta_{9}^{t} \text { Male } * \text { College }_{i}+\beta_{10}^{t} \text { Female }^{*} \text { NoCollege }_{i}\right)
\end{aligned}
$$

$\mathrm{t}=2,3,4,5,6,7,8$

The dependent variable Leaving Employment $t_{i t}$ takes value one if a respondent $(i)$ is observed transitioning out of employment because of losing their job, being laid off, taking leave, or another job status in wave $t$. We include wave fixed effects $\left(\gamma^{t}\right)$ in the model to account for the evolution over time of the COVID-19 crisis. We included interaction terms between gender and education (college or no-college) and allowed for different effects by wave $\left(\beta_{8}^{t}, \beta_{9}^{t}, \beta_{10}^{t}\right)$ to account for the different evolution of employment for these groups. We include race, the region of residence, and age controls as described in (1) above. We also control for whether the respondent reported in March that they had a job that could be performed from home and an interaction of this variable with the respondent being female. Finally, the main coefficients of interest are those for whether school-age kids are living in the household $\left(\beta_{6}\right)$ and its interaction with the respondent being female $\left(\beta_{7}\right)$. These estimated coefficients would help us understand to what extent respondents might be transitioning out of employment to take care of their children. Estimated coefficients are presented as average marginal effects in Table 6, column 1 . We obtained cluster robust standard errors at the individual level to account for the fact that we have multiple observations per respondent.

We also estimate equivalent models to (4) but focusing only on those respondents who declare they are living with school-age children in the household and substitute the variables about kids in the household for variables representing the actual division of child-care. Like we did for (3), described above, we first include dummies indicating whether the respondent ever reported being the only provider of childcare (Ever Only Me), whether the respondent reported his partner was ever the only provider of care (Ever Only My Partner), and whether they ever had help from others for childcare (Ever Others Help) (Table 6, column 2). We, then, also estimate a 
Table 6 Probability of leaving employment among those working in march (marginal effects)

\begin{tabular}{|c|c|c|c|}
\hline & $\begin{array}{l}\text { All } \\
(1)\end{array}$ & $\begin{array}{l}\text { Parents } \\
\text { (2) }\end{array}$ & $\begin{array}{l}\text { Parents } \\
\text { (3) }\end{array}$ \\
\hline Early April & $0.220 * * *(0.049)$ & $0.123 * * *(0.045)$ & $0.127 * * *(0.045)$ \\
\hline April & $0.144 * * *(0.050)$ & $0.046(0.046)$ & $0.051(0.046)$ \\
\hline Early May & $0.095^{*}(0.051)$ & $0.057(0.047)$ & $0.062(0.046)$ \\
\hline Late May & $0.101 *(0.052)$ & $-0.007(0.058)$ & $-0.001(0.058)$ \\
\hline Early June & $0.053(0.060)$ & $0.033(0.053)$ & $0.038(0.053)$ \\
\hline Late June & $0.106 *(0.059)$ & $0.069(0.059)$ & $0.070(0.058)$ \\
\hline Can Work from Home & $-0.047 * * *(0.012)$ & $-0.047 * * *(0.018)$ & $-0.048 * * *(0.017)$ \\
\hline Female* Can Work Home & $0.005(0.016)$ & $-0.000(0.021)$ & $-0.003(0.021)$ \\
\hline Female*College*Early April & $-0.027 *(0.014)$ & $-0.009(0.016)$ & $-0.001(0.016)$ \\
\hline Male*College*EarlyApril & $-0.007(0.013)$ & $-0.016(0.018)$ & $-0.013(0.017)$ \\
\hline Female*NoCollege*Early April & $-0.002(0.012)$ & $0.021(0.015)$ & $0.031 * *(0.014)$ \\
\hline Female*College*April & $-0.011(0.023)$ & $0.001(0.032)$ & $0.005(0.033)$ \\
\hline Male*College*April & $-0.010(0.024)$ & $-0.012(0.028)$ & $-0.011(0.028)$ \\
\hline Female* NoCollege*April & $0.001(0.020)$ & $0.044 *(0.026)$ & $0.053 * *(0.025)$ \\
\hline Female*College*Early May & $-0.002(0.026)$ & $-0.025(0.030)$ & $-0.021(0.030)$ \\
\hline Male* College* Early May & $0.005(0.036)$ & $-0.062(0.041)$ & $-0.060(0.041)$ \\
\hline Female*NoCollege*Early May & $0.029(0.026)$ & $-0.005(0.032)$ & $0.004(0.031)$ \\
\hline Female*College*Late May & $0.034(0.029)$ & $0.087^{*}(0.046)$ & $0.088 *(0.045)$ \\
\hline Male* College* Late May & $-0.060 *(0.035)$ & $-0.051(0.057)$ & $-0.050(0.057)$ \\
\hline Female* NoCollege*Late May & $0.001(0.031)$ & $0.036(0.045)$ & $0.043(0.045)$ \\
\hline Female*College*Early June & $0.036(0.041)$ & $-0.021(0.038)$ & $-0.017(0.038)$ \\
\hline Male*College*Early June & $0.107 * *(0.042)$ & $0.056(0.040)$ & $0.057(0.039)$ \\
\hline Female*NoCollege*Early June & $-0.006(0.050)$ & $-0.160 * * *(0.054)$ & $-0.152 * * *(0.054)$ \\
\hline Female*College*Late June & $0.022(0.046)$ & $-0.004(0.054)$ & $-0.004(0.054)$ \\
\hline Male*College* Late June & $-0.008(0.053)$ & $-0.028(0.054)$ & $-0.021(0.054)$ \\
\hline Female*NoCollege* Late June & $0.022(0.044)$ & $-0.005(0.052)$ & $0.001(0.053)$ \\
\hline Female*College*July & $0.151 * *(0.061)$ & $0.100(0.064)$ & $0.118^{*}(0.063)$ \\
\hline Female*NoCollege*July & $0.110 *(0.063)$ & $0.074(0.063)$ & $0.085(0.061)$ \\
\hline Kids & $-0.031 * * *(0.010)$ & & \\
\hline Female* Kids & $0.039 * * *(0.013)$ & & \\
\hline Care Only Me Ever & & $0.029 * * *(0.009)$ & \\
\hline Care Only My Partner Ever & & $-0.020 *(0.010)$ & \\
\hline Care Others Help & & $-0.013(0.010)$ & \\
\hline Care Always Me & & & $0.051 * * *(0.010)$ \\
\hline Observations & 9658 & 4329 & 4329 \\
\hline
\end{tabular}

Note: Standard Errors in parenthesis

$* p<0.1 ; * * p<0.05 ; * * * p<0.01$

Race, age, and region of residence controls included

Results weighted using population weights to the CPS benchmarks 
separate specification including a variable for the respondent being always the only provider of child-care in the household (Always Me) (Table 6, column 3).

\subsection{Results}

The first column of Table 5 shows the estimated marginal effects of a logit model for the probability of a respondent declaring having reduced their working hours since March among those who kept the same job since then, following the specification described in (3) above. After controlling for age, race, the region of residence, and working from home, we find no gender effect for non-parents. However, we find that college-educated mothers are significantly more likely to report that they had to reduce their working hours during this COVID-19 crisis. Both compared with working women without children and with working fathers, working mothers with a college degree are about 17 percentage points more likely to declare they reduced their working hours (relative to a mean of $35 \%$ ).

The second and third columns of Table 5 present estimates for respondents living together with school-age children in the household as a function of child-care arrangements. We find that those parents receiving help from others presented a 13 percentage points lower probability of reducing their working hours. In contrast, those parents who always reported being the only provider of childcare presented a 20 percentage points higher probability of declaring having reduced their working hours.

When focusing on those reporting having a job in March 2020, Table 6 shows the results of discrete logistic durations models for the probability of leaving employment in subsequent waves following the specification in (4) above. Overall, we observe that most of the employment transitions occurred during April. The probability of transitioning out of employment was 22 percentage points higher in early April and 14 percentage points in later April than in July. Generally, we do not find significant gender differences in transitions out of employment until July when college-educated and non-college-educated women are 15 and 11 percentage points more likely to transition out of employment than men, respectively. These estimates should be interpreted with caution, however, as most of the employment transitions occurred in April and the number of transitions decreased over time.

Having school-age children in the household is associated with a reduction in the probability of fathers leaving their employment of 3 percentage points. We do not find a significant effect on the probability of transitioning out of employment for mothers if they have school-age children in the household. The second and third columns of Table 6 present estimates for parents living together with school-age children and including variables about the division of childcare in the household. Respondents who at some point declared being the only provider of childcare in the household present a 3 percentage points higher probability of transitioning out of employment while having a partner who at some point was the only provider of care is associated with a 2 percentage points lower probability of transitioning out of employment (relative to a mean of 6\%). Finally, being always the sole provider of childcare in the household is associated with 5 percentage points higher probability of transitioning out of employment.

One important limitation of this analysis is the possibility of reverse causation from employment to care responsibilities. This would be the case if those with higher 
care responsibilities were also more likely to lose their employment involuntarily and are then more likely to provide childcare after losing their job. To test for the robustness of our results to this possibility we also estimated models that eliminated observations of those who declared they lost their job involuntarily either permanently or temporarily. These results can be found in Appendix Table 10. Although smaller in size, we still find similar effects to the ones presented in Table 6 above. Being the sole provider of care is still associated with a 2 percentage points increase in the probability of leaving employment in this case.

\section{Gender differences in psychological distress during the COVID-19 crisis}

So far, we showed that women have carried a heavier load than men in the provision of childcare during the COVID-19 crisis, even while still working. This division of childcare is associated with a reduction of working hours and an increased probability of transitioning out of employment. In this section, we explore the possible consequences that the current childcare arrangements could have in terms of gender differences on the psychological effects of the COVID-19 crisis.

\subsection{Methods}

To further study gender differences on how couples, with and without school-age children in the household, are coping in terms of psychological distress during the COVID-19 crisis, we use the following logistic regression model:

$$
\begin{aligned}
& \operatorname{Pr}\left(\text { Psychological Distress }_{i t} \mid X\right)=\Lambda\left(\beta_{0}+\gamma^{t}+\beta_{1} \text { Region }_{i}+\beta_{2} \text { Race }_{i}\right. \\
& +\beta_{3} \text { Female }_{i}+\beta_{4} \text { College }_{i}+\beta_{5} \text { Working }_{i} \\
& +\beta_{6} \text { Working } * \text { From Home }_{i}+\beta_{7}^{t} \text { Female }^{*} \text { Kids }_{i} \\
& \left.+\beta_{8}^{t} \text { Male } * \text { Kids }_{i}\right)
\end{aligned}
$$

The dependent variable Psychological Distress $i t$ is an indicator variable that takes value one if the respondent $(i)$ reported at least mild symptoms of psychological distress in a given wave $(t)$. Additionally, we estimate separate models using indicators for at least mild anxiety and mild depression symptoms using the anxiety and depression subscales separately. Our model controls for wave dummies $\left(\gamma^{t}\right)$, respondent's race, and region of residence as described in (1) above. We also include controls for respondents being female, having a college degree, currently working, and currently working from home. Finally, our main coefficients of interest correspond to interaction terms between gender and having school-age children in the household, allowing for different effects by the survey wave ${ }^{13}\left(\beta_{7}^{t}, \beta_{8}^{t}\right)$. Our reference category is males without kids in the household. We estimate cluster robust

\footnotetext{
13 As a robustness check, we also estimated models that included the lag value of the dependent psychological distress variable as an explanatory variable. Results were very much in line with the ones presented here omitting the lag. These results are available from the authors upon request.
} 
standard errors at the respondent level and present estimates as average marginal effects.

We estimate additional models, following the one described in (5), but allowing for an overall interaction of gender and school-age children in the household depending on the age of the children. In particular, we created three indicator variables that take value one if the respondent indicated that they had elementary schoolage or younger children living in the household (Kids Elementary), another variable that takes value one if the respondent indicated they had middle-school-age children in the household (Kids Middle), and a separate variable indicating if the respondent reported living with high school-age children (Kids High School). We estimate these models for all respondents who are married or living together with a partner identifying estimated effects as comparing with not having school-age children in the household. We also estimated the model just for those respondents who reported living with school-age children and used men with high school-age children as the comparison group instead. For respondents who live in the household with schoolage children, we also estimated models that include care arrangements as independent variables, equivalent to those we estimated for working hours and transitions out of employment presented above.

\subsection{Results}

Table 7 shows average marginal effects for the probability of experiencing at least mild psychological distress, at least mild anxiety, or at least mild symptoms of depression, separately. As it was shown in Fig. 4, we observe that psychological distress and anxiety symptoms peaked during April 2020. This finding does not appear to be so much the case for depression when we look at it separately. Overall, women present higher levels of psychological distress than men, a result that has been well documented in the literature before (see, e.g. Lowe et al. 2010) and during the COVID-19 pandemic for other countries (De Pedraza et al. 2020 for several countries, and Davillas and Jones 2020, Oreffice and Quintana-Domeque 2020, and Etheridge and Spantig 2020 for the U.K.).

Importantly, women with school-age children in the household experienced a higher probability of psychological distress than those without children. They experienced a 7 percentage point increase in early April and a 5 percentage point increase later in April (relative to a mean of 30\%), as compared to female respondents without school-age children in the household. This effect corresponds with a 3 percentage points increase in both anxiety and depression symptoms in early April for women with school-age children in the household. Mothers also presented a marginally statistically significant increase of 5 percentage points on the probability of presenting at least mild symptoms of psychological distress in late June. Fathers of school-age children, however, didn't experience significantly different levels of psychological distress than men without children. If anything, fathers of school-age children experienced a lower probability of at least mild symptoms of anxiety than men without school-age children by July. Having a job reduced the probability of at least mild symptoms of psychological distress by almost 10 percentage points but this effect is reduced by half when being required to work at home. 
Table 7 Probability of showing psychological distress, anxiety or depression symptoms (marginal effects)

\begin{tabular}{|c|c|c|c|}
\hline & Psychological Distress & Anxiety & Depression \\
\hline Early April & $0.086 * * *(0.021)$ & $0.058 * * *(0.016)$ & $0.011(0.014)$ \\
\hline April & $0.054 * * *(0.020)$ & $0.039 * *(0.016)$ & $0.013(0.014)$ \\
\hline Early May & $0.023(0.020)$ & $0.003(0.016)$ & $0.006(0.013)$ \\
\hline Late May & $-0.006(0.021)$ & $-0.024(0.017)$ & $0.002(0.014)$ \\
\hline Early June & $-0.008(0.022)$ & $-0.028(0.017)$ & $0.005(0.015)$ \\
\hline Late June & $-0.028(0.021)$ & $-0.023(0.017)$ & $-0.006(0.014)$ \\
\hline July & $-0.011(0.021)$ & $-0.023(0.018)$ & $-0.000(0.014)$ \\
\hline Female & $0.087 * * *(0.024)$ & $0.048 * * *(0.018)$ & $0.034 * *(0.017)$ \\
\hline Working & $-0.095 * * *(0.020)$ & $-0.062 * * *(0.014)$ & $-0.084 * * *(0.013)$ \\
\hline Work from Home & $0.043 * *(0.022)$ & $0.022(0.016)$ & $0.016(0.016)$ \\
\hline College & $0.006(0.018)$ & $0.002(0.013)$ & $-0.008(0.012)$ \\
\hline Female*Kids*Early April & $0.068 * *(0.028)$ & $0.031 *(0.019)$ & $0.031 *(0.018)$ \\
\hline Female*Kids*April & $0.051 *(0.026)$ & $0.000(0.018)$ & $0.011(0.017)$ \\
\hline Female*Kids*Early May & $0.043(0.027)$ & $-0.008(0.020)$ & $0.013(0.017)$ \\
\hline Female*Kids*Late May & $0.040(0.028)$ & $-0.005(0.022)$ & $0.014(0.018)$ \\
\hline Female*Kids*Early June & $0.036(0.029)$ & $0.003(0.023)$ & $-0.009(0.020)$ \\
\hline Female*Kids*Late June & $0.050 *(0.029)$ & $-0.009(0.023)$ & $-0.003(0.019)$ \\
\hline Female*Kids*July & $0.029(0.029)$ & $0.019(0.022)$ & $0.009(0.019)$ \\
\hline Male*Kids*Early April & $0.023(0.033)$ & $0.001(0.025)$ & $0.051 * *(0.023)$ \\
\hline Male*Kids*April & $0.016(0.032)$ & $-0.014(0.025)$ & $0.012(0.023)$ \\
\hline Male*Kids*Early May & $0.002(0.033)$ & $-0.008(0.027)$ & $-0.018(0.026)$ \\
\hline Male*Kids*Late May & $-0.015(0.035)$ & $-0.040(0.032)$ & $-0.032(0.029)$ \\
\hline Male*Kids*Early June & $-0.013(0.035)$ & $-0.054 *(0.031)$ & $-0.011(0.026)$ \\
\hline Male*Kids*Late June & $-0.034(0.037)$ & $-0.099 * * *(0.035)$ & $0.013(0.026)$ \\
\hline Male*Kids*July & $-0.063 *(0.038)$ & $-0.068 * *(0.034)$ & $-0.028(0.029)$ \\
\hline Observations & 20,935 & 20,938 & 20,950 \\
\hline
\end{tabular}

Note: Standard Errors in parenthesis

$* p<0.1 ; * * p<0.05 ; * * * p<0.01$

Wave, race, and region of residence controls included

Results weighted using population weights to the CPS benchmarks

The first column of Table 8 presents, for all respondents who are married or living together with a partner, overall estimates of the effects of living with school-age children in the household by age of the children (elementary school-age children, middleschool-age children, or high school-age children) as compared to not having school-age children in the household. In contrast, column 2 of Table 8 presents results only for those living with school-age in the household using men with high school-age children as the comparison. In both cases, we observe that the higher levels of psychological distress observed for mothers of school-age children appear to be driven by those who reported living with elementary school-age or younger children in the household. Mothers of elementary school-age or younger children present an almost 5 percentage points increase in the probability of presenting at least mild psychological distress 
Table 8 Probability of showing psychological distress (marginal effects)

\begin{tabular}{|c|c|c|c|c|}
\hline & $\begin{array}{l}\text { All } \\
\text { (1) }\end{array}$ & $\begin{array}{l}\text { Parents } \\
\text { (2) }\end{array}$ & $\begin{array}{l}\text { Parents } \\
\text { (3) }\end{array}$ & $\begin{array}{l}\text { Parents } \\
\text { (4) }\end{array}$ \\
\hline Early April & $0.113 * * *(0.018)$ & $0.146 * * *(0.030)$ & $0.145^{* * *}(0.031)$ & $0.145 * * *(0.031)$ \\
\hline April & $0.075^{* * * *}(0.018)$ & $0.102 * * *(0.030)$ & $0.093 * * *(0.031)$ & $0.093 * * *(0.031)$ \\
\hline Early May & $0.039 * *(0.018)$ & $0.061^{* *}(0.031)$ & $0.054 *(0.032)$ & $0.055^{*}(0.032)$ \\
\hline Late May & $0.005(0.018)$ & $0.022(0.031)$ & $0.014(0.032)$ & $0.014(0.032)$ \\
\hline Early June & $0.003(0.019)$ & $0.019(0.030)$ & $0.009(0.032)$ & $0.008(0.031)$ \\
\hline Late June & $-0.017(0.018)$ & $-0.001(0.030)$ & $-0.011(0.031)$ & $-0.012(0.031)$ \\
\hline July & $-0.012(0.019)$ & $-0.008(0.032)$ & $-0.010(0.033)$ & $-0.011(0.033)$ \\
\hline Female & $0.096 * * *(0.024)$ & $0.125^{* *}(0.056)$ & $0.142 * * *(0.031)$ & $0.134 * * *(0.028)$ \\
\hline Working & $-0.097 * * *(0.020)$ & $-0.093 * * *(0.027)$ & $-0.097 * * *(0.029)$ & $-0.095 * * *(0.028)$ \\
\hline Working from Home & $0.042 *(0.022)$ & $0.019(0.029)$ & $0.020(0.030)$ & $0.019(0.030)$ \\
\hline College & $0.007(0.018)$ & $0.009(0.026)$ & $0.017(0.026)$ & $0.015(0.026)$ \\
\hline Female*Kids Elementary & $0.049 * *(0.024)$ & $0.069 *(0.039)$ & & \\
\hline Female* Kids Middle & $0.026(0.032)$ & $0.032(0.034)$ & & \\
\hline Female*Kids High School & $0.004(0.031)$ & $0.014(0.036)$ & & \\
\hline Male*Kids Elementary & $0.019(0.028)$ & $0.072 *(0.040)$ & & \\
\hline Male* Kids Middle & $-0.008(0.042)$ & $0.019(0.041)$ & & \\
\hline Male* Kids High & $0.020(0.036)$ & & & \\
\hline Care Only Me Ever & & & $0.031(0.030)$ & \\
\hline Care Only Partner Ever & & & $0.043(0.032)$ & \\
\hline Care Others Help & & & $-0.008(0.030)$ & \\
\hline Care Always Me & & & & $0.019(0.032)$ \\
\hline Observations & 20,935 & 9587 & 8821 & 8821 \\
\hline
\end{tabular}

Note: Standard Errors in parenthesis

$* p<0.1 ; * * p<0.05 ; * * * p<0.01$

Wave, race, and region of residence controls included

Results weighted using population weights to the CPS benchmarks

symptoms when compared to women without children and almost a 7 percentage points increase when focusing on parents and compared with fathers of high school children. Fathers of elementary school-age and younger children also experience a 7 percentage points higher probability of at least mild symptoms of psychological distress when compared with fathers of high school-age children. Finally, columns 3 and 4 of Table 8 study the relationship between care arrangements and psychological distress among respondents living with school-age children in the household. In this case, we do not observe a significant relationship between psychological distress and who is responsible for providing most of the childcare.

\section{Conclusions}

The unprecedented school-closures, social distancing measures, and stay-at-home orders to contain the COVID-19 pandemic have the potential to drastically magnify gender differences in terms of both childcare arrangements and work. In this paper, we use unique and rich nationally representative longitudinal data for the U.S. collected every two weeks, from March to July 2020, to document how couples are 
coping with this crisis in terms of childcare provision, employment, working arrangements, and psychological distress levels. We document important gender differences in childcare arrangements of school-age children in the household. Current childcare arrangements do appear to be associated with changes in working hours and lower levels of employment attachment. We also document a new small gap in psychological distress that emerged between mothers and women without school-age children in the household in early April, which appears to be driven by higher levels of psychological distress reported by mothers of elementary school-age and younger children.

Among working mothers who are married or living together with a partner, one out of three reports being the only provider of care for their school-age children during the school closures, as compared to one out of ten working fathers. This is a sizable difference. Working mothers were 17 percentage points more likely than working fathers to become the sole childcare provider between April and July 2020, even when they were not initially in April. Mothers appear to provide more childcare despite their current working status. Being "currently working" appears to have a more limited influence on the childcare responsibilities of mothers than on the childcare responsibilities of fathers. Although we lack data before the COVID-19 crisis and can't study how childcare arrangements have changed due to this crisis, our results go in line with those of others who show that, although the sharing of household chores increased during the lockdown, the burden for women still increased during this period and remained higher than that for men (See, Biroli et al. 2020; Del Boca et al. 2020; Farré et al. 2020).

Childcare responsibilities are related to changes in working hours and an increased probability of transitioning out of employment. College-educated mothers are significantly more likely to report that they had to reduce their working hours during the COVID-19 crisis. Parents who always reported being the sole provider of childcare presented a 20 percentage points higher probability of declaring having reduced their working hours, a $57 \%$ increase relative to a mean of $35 \%$. In terms of transitioning out of employment, parents who at some point declared being the only provider of childcare in the household present a 3 percentage points higher probability of transitioning out of employment, while being always the sole provider of childcare in the household is associated with 5 percentage points higher probability of transitioning out of employment. Relative to a mean of $6 \%$ transitions out of employment, these are both sizeable effects.

In terms of psychological distress, we observe a new gap in psychological distress that emerged between mothers and women without school-age children in the household in early April. These effects appear to be driven by those who reported living with elementary school-age children in the household. Fathers of school-age children, however, didn't experience significantly different levels of psychological distress than men without children. If anything, fathers of school-age children experienced a lower probability of at least mild symptoms of psychological distress than men without school-age children by July. We do not observe, however, a significant relationship between psychological distress and childcare arrangements in the household. Using data from 25 countries collected from March 23 to April 30, 2020, De Pedraza et al. (2020) show that the presence of children in the household did not affect how often women report feelings of anxiety. However, our findings for 
women with children do not line up with these country averages, thus suggesting that different labor market and family policies and norms across countries may affect psychological distress levels in parents.

The conclusion of the rapidly evolving literature on the effects of the COVID19 crisis is that working women have been affected in different ways by the pandemic, depending on their demographics and job characteristics. Less-educated women are more likely to work in sectors where remote work is not possible, and thus employment loss has been larger. More highly educated women are more likely to be able to work from home, which has protected their employment in the short run. Parents in general have had to increase their hours caring for their children. Mothers used to do disproportionately more housework and childcare than fathers before the crisis, and the pattern remains during the pandemic. This finding implies that mothers who continue working have new demands on their time during the pandemic, notably caring for their children and helping them with their homework and remote learning, especially the mothers of young children. These additional tasks can put a strain on mothers' time. We find evidence of that, as we see that mothers are more likely to reduce their hours worked and to suffer psychological distress.

The empirical facts we document are in line with some findings from this emerging literature on the gender effects of the COVID-19 crisis and connect some of the facts that have been studied in isolation in previous work. Like Collins et al. (2020), we document significant gender differences in the reduction of working hours among parents, especially for college-educated respondents. We also find a positive association between childcare responsibilities and a reduction of working hours and increased transitions out of employment. Given that there are high returns to experience, especially for women (Olivetti 2006), our findings suggest that women may bear the consequences of this crisis even after it is over. Alon et al. (2020) conjecture that perhaps the increased prevalence of flexible work arrangements and fathers taking increasing responsibility for childcare, compared to previous recessions, are forces that could promote gender equality in the labor market in the medium or long term. Our findings are not very optimistic in this respect, as mothers continue to shoulder the bulk of the increased time demands, potentially at the expense of their work prospects. The facts we find raise concerns about the implications of this crisis for the evolution of the careers of women, particularly the mothers of young children.

As this crisis persists over time, and the future of school reopening plans are unclear, the middle-term gender differences reported in this paper could have longerterm implications and represent a step back in terms of gender equality. The fact that we observe significant gender differences in the reduction of working hours among parents, especially for college-educated respondents, and a positive association between childcare responsibilities and a reduction of working hours and increased transitions out of employment is worrisome as these job interruptions could have negative effects on working mothers' wages and careers (see, e.g. Baum 2003). Also, documented differences in the prevalence of psychological distress among mothers and women without school-age children could have important longer-term implications not only for the health of mothers but also for their children's health and development (see, e.g. Farahati et al. 2003; Frank and Meara 2009; Bratti and 
Mendola 2014; Le and Nguyen 2017). In future work, we plan to continue studying the longer-term effects that the COVID-19 crisis is having on working mothers.

Data availability All data used in this paper is publicly available upon registration at https://uasdata. usc.edu/index.php.

Code availability Estimates in this paper were obtained using the STATA-15 software. Code available from the authors upon request.

Acknowledgements The project described in this paper relies on data from surveys administered by the Understanding America Study (UAS), which is maintained by the Center for Economic and Social Research (CESR) at the University of Southern California. The content of this paper is solely the responsibility of the authors and does not necessarily represent the official views of USC or UAS. We give thanks to Francisco Perez-Arce for his help with the data during the first stages of this work. We are thankful to our partners for providing childcare so we could write this paper during these challenging times.

\section{Compliance with ethical standards}

Conflict of interest The authors declare that they have no conflict of interest.

Publisher's note Springer Nature remains neutral with regard to jurisdictional claims in published maps and institutional affiliations.

\section{Appendix}

Table 9 presents the estimated coefficients of a discrete duration model for the probability of an increase in childcare responsibilities. The specification follows the model described in the main text in (2), but the dependent variable is an indicator for the transition between "Others Help" or "Only My Partner" to an increased childcare responsibility of "Only Both", or "Only Me". Similarly, to the results

Table 9 Probability of transitioning from childcare responsibilities arrangements "Others Help" or "Only My Partner" to "Only both" or "Only me"

\begin{tabular}{lrrr}
\hline & All Parents & Working Parents & \multicolumn{1}{c}{ Same Job } \\
\hline Female & $0.093^{* *}(0.046)$ & $0.131^{* * *}(0.046)$ & $0.146^{* *}(0.059)$ \\
College & $0.119^{* * *(0.037)}$ & $0.060(0.039)$ & $0.072(0.046)$ \\
Female*College & $-0.123^{* *}(0.051)$ & $-0.096^{*}(0.057)$ & $-0.108(0.066)$ \\
Working & $-0.113^{* * *(0.041)}$ & & \\
Female*Working & $0.063(0.053)$ & & \\
Working from Home & & $0.094^{* * *(0.035)}$ & $0.082^{*}(0.043)$ \\
Female* Working Home & 1377 & $-0.036(0.055)$ & $-0.020(0.064)$ \\
N. Obs & & 924 & 709 \\
\hline
\end{tabular}

Note: Standard Errors in parenthesis

$* p<0.1 ; * * p<0.05 ; * * * p<0.01$

Wave, race, age, and region of residence controls included. Results weighted using population weights to the CPS benchmarks 
Table 10 Determinants of the probability of exiting employment (eliminating involuntary job terminations)

\begin{tabular}{|c|c|c|c|}
\hline & All & Parents & Parents \\
\hline Early April & $0.035 * *(0.015)$ & $0.009(0.017)$ & $0.009(0.018)$ \\
\hline April & $0.003(0.016)$ & $-0.025(0.019)$ & $-0.026(0.019)$ \\
\hline Early May & $-0.013(0.016)$ & $-0.023(0.020)$ & $-0.024(0.020)$ \\
\hline Late May & $-0.007(0.015)$ & $-0.026(0.018)$ & $-0.027(0.017)$ \\
\hline Early June & $-0.008(0.016)$ & $-0.014(0.019)$ & $-0.015(0.019)$ \\
\hline Late June & $-0.001(0.018)$ & $-0.007(0.020)$ & $-0.009(0.020)$ \\
\hline Can Work from Home & $-0.016^{*}(0.009)$ & $-0.027 *(0.014)$ & $-0.026^{*}(0.014)$ \\
\hline Female* Can Work Home & $-0.008(0.012)$ & $-0.002(0.016)$ & $-0.004(0.016)$ \\
\hline Female & $0.003(0.007)$ & $0.022 * *(0.011)$ & $0.026 * * *(0.010)$ \\
\hline College & $-0.007(0.008)$ & $0.008(0.013)$ & $0.010(0.012)$ \\
\hline Female*College & $0.002(0.010)$ & $-0.013(0.015)$ & $-0.016(0.014)$ \\
\hline Kids & $-0.020 * *(0.008)$ & & \\
\hline Female* Kids $^{*}$ & $0.026^{* * *}(0.010)$ & & \\
\hline Care Only Me Ever & & $0.007(0.006)$ & \\
\hline Care Only My Partner Ever & & $-0.013 *(0.008)$ & \\
\hline Care Others Help & & $-0.015^{* *}(0.008)$ & \\
\hline Care Always Me & & & $0.019 * *(0.008)$ \\
\hline Observations & 9385 & 4202 & 4202 \\
\hline
\end{tabular}

Note: Standard Errors in parenthesis

$* p<0.1 ; * * p<0.05 ; * * * p<0.01$

Race, age, and region of residence controls included. Results weighted using population weights to the CPS benchmarks

presented in Table 4, in this specification, we also find that mothers are more likely to have increased their childcare responsibilities than fathers in this period, even when conditioning for their working situation.

To further investigate gender and childcare effects on the decision to leave their jobs, Table 10 presents the coefficients from the model described in the main text in (4) but estimated eliminating respondents who declared they lost their job involuntarily either permanently or temporarily.

\section{References}

Adams-Prassl, A., Boneva, T., Golin, M., \& Rauh, C. (2020). Inequality in the impact of the coronavirus shock: Evidence from real time surveys. IZA Discussion Paper No. 13183, April 2020. http://ftp.iza. org/dp13183.pdf.

Aguiar, M., \& Hurst, E. (2007). Measuring trends in leisure: the allocation of time over five decades. The Quarterly Journal of Economics, 122(3), 969-1006.

Alon, T. M., Doepke, M., Olmstead-Rumsey, J., \& Tertilt, M. (2020). The impact of COVID-19 on gender equality. National Bureau of Economic Research Working Paper No. 2697. https://www.nber.org/pa pers/w26947. 
Andrew, A., Cattan, S., Costa Dias, M., Farquharson, C., Kraftman, L., Krutikova, S., Phimister, A., Sevilla, A. (2020), "How are mothers and fathers balancing work and family under lockdown?" IFS Briefing Note BN290. https://www.ifs.org.uk/uploads/BN290-Mothers-and-fathers-balancing-work-a nd-life-under-lockdown.pdf.

Baker, M., Gruber, J., \& Milligan, K. (2008). Universal child care, maternal labor supply, and family wellbeing. Journal of Political Economy, 116(4), 709-745.

Baum, C. L. (2003). The effects of work interruptions on women's wages. Labour, 16, 1-37.

Beland, L. P., Brodeur, A., \& Wright, T. (2020). COVID-19, stay-at-home orders and employment: Evidence from CPS data. IZA Discussion Paper No. 13282, May 2020. http://ftp.iza.org/dp13282.pdf.

Bick, A. (2016). The quantitative role of child care for female labor force participation and fertility. Journal of the European Economic Association, 14(3), 639-668.

Biroli, B., Bosworth, S., Della Giusta, M., Di Girolamo, A., Jaworska, S., \& Vollen, J. (2020). Family Life in Lockdown. Manuscript retrieved here: http://conference.iza.org/conference_files/COVID_Youth/ biroli_p9260.pdf.

Bratti, M., \& Mendola, M. (2014). Parental health and child schooling. Journal of Health Economics, 35, 94-108.

Collins, C., Landivar, L. C., Ruppanner, L., \& Scarborough, W. J. (2020). COVID-19 and the Gender Gap in Work Hours. Gender, Work \& Organization. https://doi.org/10.1111/gwao.12506.

Davillas, A., \& Jones, A. M. (2020). The COVID-19 pandemic and its impact on inequality of opportunity in psychological distress in the UK, SSRN Working Paper May 2020. https://papers.ssrn.com/sol3/pa pers.cfm?abstract_id=3614940.

De Pedraza, P., Guzi, M., \& Tijdens, K. (2020). Life Dissatisfaction and Anxiety in COVID-19 pandemic, Global Labor Organization Working Paper No. 544. https://www.econstor.eu/bitstream/10419/ 217053/1/GLO-DP-0544.pdf.

Del Boca, D., Oggero, N., Profeta, P., \& Rossi, M. (2020). Women's and men's work, housework and childcare, before and during COVID-19. Review of Economics of the Household, 18, 1001-1017.

Domeij, D., \& Klein, P. (2013). Should day care be subsidized? Review of Economic Studies, 80(2), $568-595$.

Etheridge, B., \& Spantig, L. (2020). The gender gap in mental well-being during the Covid-19 outbreak: evidence from the UK. Institute for Social and Economic Research Working Paper No. 2020-08. https://www.iser.essex.ac.uk/research/publications/working-papers/iser/2020-08.

Farahati, F., Marcotte, D. E., \& Wilcox-Gök, V. (2003). The effects of parents' psychiatric disorders on children's high school dropout. Economics of Education Review, 22, 167-178.

Farré, L., Fawaz, Y., Gonzalez, L., \& Graves, J. (2020). How the COVID-19 lockdown affected gender inequality in paid and unpaid work in Spain. IZA Discussion Paper No. 13434, July 2020. http://ftp. iza.org/dp13434.pdf.

Frank, R.G., \& Meara, E. (2009). The effect of maternal depression and substance abuse on child human capital development. National Bureau of Economic Research Working Paper No. 15314. https:// www.nber.org/papers/w15314.

Gorsuch, M. M. (2016). Decomposing the increase in men's time on childcare during the great recession. Review of Economics of the Household, 14(1), 53-82.

Heckman, J. J. (1974). Effects of child-care programs on women's work efforts. The Journal of Political Economy, 82(2), S136-S163.

Heggeness, M. (2020). Why is mommy so stressed? Estimating the immediate impact of the COVID-19 shock on parental attachment to the labor market and the double bind of mothers. Federal Reserve Bank of Minneapolis Institute Working Paper No. 33. https://www.minneapolisfed.org/institute/ working-papers-institute/iwp33.pdf.

Kalenkoski, C. M., \& Pabilonia, S. W. (2020). Initial impact of the COVID-19 pandemic on the employment and hours of self-employed coupled and single workers by gender and parental Status. IZA Discussion Paper No. 13443, July 2020. http://ftp.iza.org/dp13443.pdf.

Kroenke, K., Spitzer, R. L., Williams, J. B. W., \& Löwe, B. (2009a). An ultra-brief screening scale for anxiety and depression: the PHQ-4. Psychosomatics, 50, 613-621.

Kroenke, K., Strine, T. W., Spritzer, R. L., Williams, J. B., Berry, J. T., \& Mokdad, A. H. (2009b). The PHQ8 as a measure of current depression in the general population. J Affect Disord, 114(1-3), 163-73.

Le, H. T., \& Nguyen, H. T. (2017). Parental health and children's cognitive and noncognitive development: New evidence from the longitudinal survey of Australian children. Health Economics, 26, 1767-1788.

Lowe, B., Wahl, I., Rose, M., Spitzer, C., Glaesmer, H., \& Wingeneld, K., et al. (2010). A 4-item measure of depression and anxiety: Validation and standardization of the Patient Health Questionnaire-4 (PHQ-4) in the general population. Journal of Affective Disorders, 122, 86-95. 
Mongey, S., \& Weinberg, A. (2020). Characteristics of workers in low work-from-home and high personal-proximity occupations. Becker Friedman Institute for Economic White Paper, April 2020. https://bfi.uchicago.edu/working-paper/characteristics-of-workers-in-low-work-from-home-and-highpersonal-proximity-occupations/.

Montenovo, L., Jiang, X., Rojas, F. L., Schmutte, I. M., Simon, K. I., Weinberg, B. A., et al. (2020). Determinants of disparities in covid-19 job losses. National Bureau of Economic Research Working paper No. 27132. https://www.nber.org/papers/w27132.

Olivetti, C. (2006). Changes in women's aggregate hours of work: The role of returns to experience. Review of Economic Dynamics, 9(4), 557-587.

Oreffice, S., \& Quintana-Domeque, C. (2020). Gender Inequality in COVID-19 Times: Evidence from UK Prolific Participants. IZA Discussion Paper No. 13463, July 2020. http://ftp.iza.org/dp13463.pdf.

Sevilla, A., \& Smith, S. (2020). Baby steps: The gender division of childcare during the COVID19 pandemic. IZA Discussion Paper No. 13302, May 2020. http://ftp.iza.org/dp13302.pdf.

Schoonbroodt, A. (2018). Parental child care during and outside of typical work hours. Review of Economics of the Household, 16(2), 453-476.

Spitzer, R. L., Kroenke, K., Williams, J. B. W., \& Lowe, B. (2006). A brief measure for assessing generalized anxiety disorder. Arch Inern Med, 166, 1092-1097.

Villadsen, A., Conti, G., \& Fitzsimons, E. (2020). Parental involvement in home schooling and developmental play during lockdown - Initial findings from the COVID19 Survey in Five National Longitudinal Studies. London: UCL Centre for Longitudinal Studies.

Zamarro, G. (2020). Family labor participation and childcare decisions: the role of grannies. SERIEs, 11, $287-312$. 